\title{
Vivir - Habitar- Convivir: Cinco reflexiones sobre sostenibilidad para la formación del Arquitecto
}

\author{
Live - Inhabit - Live (together) with: Five reflections on sustainability for \\ Architect training
}

\section{Viver - Morar - Conviver: Cinco reflexões sobre sustentabilidade para treinamento de Arquitetos}

María Auxiliadora Linares Bermúdez

Arquitecto, P.h.D. en Arquitectura, Universidad del Zulia. Venezuela.

mariaauxlinares@fad.luz.edu

(iD) https://orcid.org/0000-0001-6488-9759

Recibido: junio 8 de 2020

Aceptado: agosto 27 de 2020

Publicado: septiembre 30 de 2020

\section{RESUMEN}

El respeto por los espacios habitables, debe partir de un sistema de valores promotores de buenas prácticas para el hacer. La presente reflexión forma parte de una diagnosis sobre la praxis en el escenario del proceso de aprendizaje del Diseño Arquitectónico, para guiar a los estudiantes hacia la proyectación de propuestas con criterios de sostenibilidad, más allá de posturas teóricas recurrentes. Se abordan cinco reflexiones a modo de interrogantes, surgidas de la preocupación por la sostenibilidad, su práctica en los espacios habitables, la experiencia docente del Diseño Arquitectónico, así como consideraciones sobre el hacer académico de la Arquitectura.

Palabras clave: Sostenibilidad; habitar; aprendizaje; docencia; Diseño Arquitectónico

\begin{abstract}
Respect for habitable spaces must start from a system of values that promote good practices for doing. This reflection is part of a diagnosis on the praxis in the setting of the Architectural Design learning process, to guide students towards projecting proposals with sustainability criteria, beyond recurring theoretical positions. Five reflections are addressed as questions, arising from the concern for sustainability, its practice in living spaces, the teaching experience of Architectural Design, as well as considerations about the academic doing of Architecture.
\end{abstract}

Keywords: Sustainability; live; learning; teaching; Architectural Design 


\section{RESUMO}

O respeito pelos espaços habitáveis deve partir de um sistema de valores que promova boas práticas de fazer. Esta reflexão faz parte de um diagnóstico sobre a práxis na configuração do processo de aprendizagem do Projeto de Arquitetura, para orientar os alunos a projetar propostas com critérios de sustentabilidade, para além de posicionamentos teóricos recorrentes. Cinco reflexões são abordadas como questionamentos, oriundos da preocupação com a sustentabilidade, sua prática nos espaços de convivência, a experiência docente do Projeto de Arquitetura, bem como considerações sobre o fazer acadêmico da Arquitetura.

Palavras-chave: Sustentabilidade; viver; Aprendendo; ensino; Projeto Arquitetônico.

Qué tipo de mundo queremos dejar a quienes nos sucedan, a los niños que están creciendo?

Papa Francisco (2015)

\section{INTRODUCCIÓN}

El acto de reflexionar generalmente parte de cuestionamientos que se hacen cuando algo ocupa la atención o, como en este caso particular, cuando algo preocupa. De modo que estas cavilaciones tienen como origen la inquietud como persona, como profesional de la Arquitectura y como profesora universitaria en el área, sobre cómo abordar el proceso educativo para la sostenibilidad, para una vida congruente con uno mismo desde el aprender a hacer de la Arquitectura. Al hacer referencia al vivir, a los fines de estas reflexiones, se está aludiendo al solo hecho de existir, de tener vida o estar vivo. Este término se concibe de un modo ampliado, cuando ese vivir se hace en un contexto y en unas condiciones, a la manera de Heidegger, para una existencia en función del cuidado. De ese modo, "El rasgo fundamental del habitar es este cuidar (custodiar, velar por). Este rasgo atraviesa el habitar en toda su extensión." (Heidegger, 1951, p.3)

Comenzando por lo básico, la definición de sostenibilidad, apunta hacia algo o alguien que puede mantenerse en pie por sí mismo, sin necesitar apoyos que puedan comprometer a otro o causarle perjuicio, lo cual conduce a una noción de equilibrio. Algunas definiciones relacionan la sostenibilidad únicamente con la ecología y la economía (Real Academia de la Lengua Española, 2020, s/p.). No obstante, se evidencia su real relación con todo lo que rodea al ser humano, sea natural o edificado. En consecuencia, se puede afirmar que los seres humanos, en tanto que parte de lo natural sobre el planeta, poseen o no cualidades de sostenibilidad.

Lo anterior, encuentra fundamento en la noción de paisaje cultural y en la manera cómo este interviene para la definición del hábitat, proveniente de la dialógica permanente entre naturaleza y cultura. De modo que "...el paisaje cultural como construcción social es un producto en constante transformación y se convierte en una herramienta importante para aportar a la comprensión de la construcción del hábitat..." (Esteves y Sales, 2018, p.3). Sin embargo, las huellas que va dejando la humanidad y su cultura en la naturaleza, no son dignas de orgullo.

Al comparar esos conceptos con las realidades urbanas, se está consciente $y$, hasta se es coincidente, sobre el hecho que el ser humano, hoy por hoy, habita ciudades, lugares y espacios insostenibles, esto es, que no pueden mantenerse en pie por sí mismos, y en esa condición están afectando negativamente a otras áreas, a otras realidades. Solo basta con volver la mirada a espacios naturales alrededor del mundo y observar, con estupor, su cada vez más constante y agravada afectación, derivada del accionar humano en su irresistible deseo por poseer un lugar. De esa manera, sigue vigente la afirmación: "La auténtica penuria del habitar reside en el hecho de que los mortales primero tienen que buscar primero la esencia del habitar; de que tienen que aprender primero a habitar" (Heidegger, 1951, p.8)

De ese darse cuenta de las necesidades del habitar con criterios de sostenibilidad, se desprenden acciones como congresos, simposios, conferencias y una serie de múltiples actividades que han tenido y tienen como centro el compartir conocimientos, preocupaciones y reflexiones en torno a la sostenibilidad, al desarrollo sostenible $y$, en el caso de la Arquitectura y su aprendizaje, al diseño arquitectónico sostenible, con una visión prospectiva hacia un futuro inmediato donde la dedicación no se centre únicamente a debatir sobre sostenibilidad, sino que se oriente a vivir, habitar, actuar, proyectar y construir con criterios que hagan posible el desarrollo sostenible en el tiempo, como premisa de vida individual y colectiva.

Sobre esa proposición, un proyecto sostenible puede ser concebido como un conjunto interrelacionado de "...espacios saludables, viables económicamente y sensibles a las necesidades sociales. Supone respetar 
los sistemas naturales y aprender de los procesos ecológicos." (Edwards, 2009, p.3). Lo anterior, amerita promover desde el aula investigaciones en áreas, si se quiere, distintas a la Arquitectura, no obstante, relacionadas estrechamente, como la Biología, la Ecología, la Ingeniería Ambiental, entre otras, en busca de aprender de la interacción ser humano-ambiente natural, donde el primero involucra necesariamente el ambiente construido y su impacto en él. Las consideraciones anteriores, mueven a compartir algunas reflexiones sobre la necesidad de una docencia orientada hacia el aprendizaje de la Arquitectura con criterios de sostenibilidad (ver Figura 1).

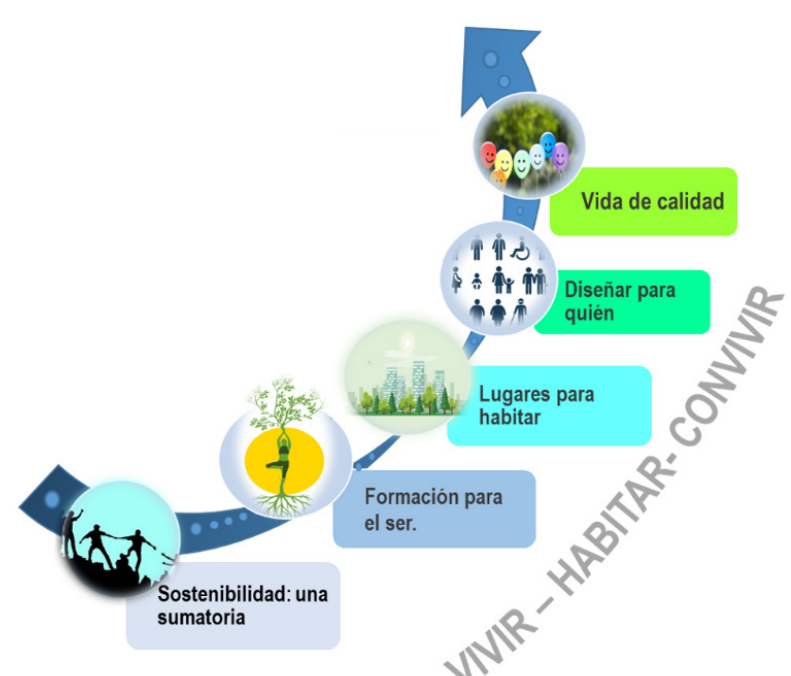

Figura 1. Cinco Reflexiones sobre Sostenibilidad para la Formación del Arquitecto.

Fuente: Linares (2020). Imágenes tomadas de https://pixabay.com/es/

\section{1a. Reflexión. Sostenibilidad: Una Sumatoria}

La sostenibilidad debe empezar por el individuo, trasladarse a la familia y de ahí a la sociedad, multiplicándose en una suerte de aspersor que riegue continuamente las vidas humanas. Se hacen continuos esfuerzos por introducir el concepto de desarrollo sostenible, sin embargo, su concreción a nivel de valores sociales ha sido difícil y, aunque todo apunta a la educación desde temprana edad, el sistema educativo adolece fallas graves que aún no ha logrado salvar producto de la fraccionada visión del conocimiento.

Cada vez es más patente, que se vive para la insostenibilidad, se producen desechos en cantidades ilimitadas, sin una real capacidad para reciclarlos a la misma velocidad. No se recupera, no se repara, no se adecúa. Antes bien, se prefiere desechar y comprar de nuevo. No se trata de una crítica al consumismo, se trata de asumir una actitud más consciente, menos dilapidaría de los recursos y los productos terminados. Se trata de ser empático con el medio, con el contexto, con el lugar en que se habita, donde se mueven las personas, donde pertenecen. No se trata de un tema estético, porque afea las ciudades y los espacios, se trata de un tema ético que compete a la moral y al sentido del buen vivir.

Aquí, la educación tiene un papel protagónico para la formación de personas y sociedades conscientes de la necesidad de conservar el mundo con criterios de sostenibilidad. Desde las familias, pasando por la escuela en todos sus niveles y modalidades, hasta las universidades en pre y posgrado, la sostenibilidad debe ser un eje transversal con un seguimiento acompasado, continuo, constante, acompañado de buenas prácticas en todos los ámbitos. Y no solo en el nivel de la academia formal, sino también en lo no académico, a través de los medios de comunicación y las redes sociales, de los entes gubernamentales en los niveles macro, meso y micro.

Resulta necesario entender que las instituciones, empresas y demás organismos tienen en la sostenibilidad un punto de apoyo impulsor de acciones desde cada ámbito, para abordar una vida con armonía. Si esto no se inicia en la conciencia del individuo desde la educación, ¿cómo entonces se puede lograr un desarrollo sostenible en un lugar, en una ciudad, un país, en el planeta? "La educación en la responsabilidad ambiental puede alentar diversos comportamientos que tienen una incidencia directa e importante en el cuidado del ambiente. (Francisco, 2015, p. 161), y a ello se agrega, "Los ámbitos educativos son diversos: la escuela, la familia, los medios de comunicación, la catequesis, etc. Una buena educación escolar en la temprana edad coloca semillas que pueden producir efectos a lo largo de toda una vida..." (Francisco, 2015, p.162)

De esa manera, la educación es la puerta de acceso principal que tiene una ciudad, una región y un país para promover, desde el conocimiento, el hacer y las vivencias, el desarrollo sostenible junto a otros valores intrínsecos a este, como la responsabilidad, la ayuda mutua y la generosidad, entre otros. Es vital sensibilizar a los más pequeños y luego, dentro de la educación formal, ir reforzando en cada etapa. No es solo responsabilidad de maestros, biólogos, ambientalistas, arquitectos, ingenieros, geógrafos o veterinarios, también de quienes legislan y de quienes hacen cumplir las leyes, del personal de salud que debe orientarse a medicina preventiva, de administradores que deben utilizar eficientemente 
los recursos disponibles. Es en las buenas prácticas, donde se afianzar la sostenibilidad como vivencia diaria y no como moda pasajera, efímera o responsabilidad de unos pocos.

\section{2a. Reflexión. ¿Educación para el Hacer o Formación para el Ser?}

En las universidades, ¿qué se está haciendo y qué se debe hacer para promover el desarrollo sostenible? La respuesta a esta pregunta es una latente reflexión a la que están llamados a hacerse todos los actores dentro de la educación universitaria. No sólo profesores y estudiantes, también autoridades, personal administrativo y personal obrero, todos deben cuestionarse en su hacer particular, a aportar en la promoción, alcance y mantenimiento de espacios sostenibles en el tiempo. Las prácticas actuales serán el reflejo de la vida futura, en tanto se tenga un actuar proclive a la sostenibilidad, en esa medida estará aportando para un desarrollo sostenible. Y se habla desde la actuación, toda vez que desde la teoría mucho se ha escrito; la literatura da cuenta de ello: investigaciones, constituciones, leyes, normas, currícula escolares en todos los niveles, programas, artículos, ponencias, entre otros materiales que se tienen a mano para documentarnos. $Y$, en la práctica, ¿dónde queda esa teoría?

$\mathrm{Al}$ analizar las consideraciones sobre el hecho que "El Arquitecto es un ser social y como tal aprende en su hogar, en su medio social y cultural y en el espacio reservado para él en el mundo universitario. Las escuelas o facultades de Arquitectura son socialmente responsables de la formación profesional de Arquitectos. La educación entendida en toda su amplitud, es la responsable de formar personalidades." (Palacio, 2016. P.39). Se evidencia la magnitud de la responsabilidad compartida que tienen los profesores de Arquitectura, la cual va más allá de enseñar a proyectar teniendo en cuenta las variables arquitectónicas. Los profesores aportan en el desarrollo de las personalidades de sus estudiantes. Tarea esta que, en innumerables ocasiones, lamentablemente, en las universidades se pasa por alto, bien por no darse cuenta o bien por considerar que no es propia de un profesor universitario tal acción.

Si la sostenibilidad inicia en el individuo, ¿qué se puede hacer para que los estudiantes desarrollen competencias hacia la sostenibilidad? En el contexto de la Arquitectura, al revisar los Programas de Estudio efectivamente se encuentran contenidos sobre el desarrollo sostenible y se promueven aprendizajes en ese sentido. Aprendizajes que evalúan los profesores de Diseño Arquitectónico, sobre la base de su aplicación en un proyecto. Sin embargo, cabe la pregunta: después que se presenta ese proyecto ¿qué sucede con ese estudiante?, ¿hay seguimiento en las subsecuentes asignaturas?, ¿podrían realizarse actividades intra o extra curriculares que apoyen el trabajo personal con el estudiante?

Tres son las áreas a las que apunta la propuesta de Educación para el Desarrollo Sostenible: Educación Ecológica, Educación para el Desarrollo Humano y Formación para una Ciudadanía Democrática (Gabaldón, 2006). A los fines de este papel de trabajo, solo se considerará la segunda área, que el autor define como aquella "... orientada a preparar a los individuos para enfrentar los retos sociales y económicos planteados para el progreso humano." (Gabaldón, p.235). Desde una visión particular, se considera que los aspectos ecológicos, por una parte, y la formación ciudadana democrática, por la otra, forman parte intrínseca de esos retos sociales y económicos. La educación no puede seguir siendo abordada de un modo compartimentado; ya se ha padecido bastante por ello como humanidad. Por tanto, existe la "...necesidad de dar paso al nuevo paradigma del desarrollo sustentable" (Gabaldón, p.235). ¿Y acaso ese desarrollo no se plantea complejo y sistémico?

Se ha escrito numerosa literatura sobre sistemas y complejidad, sin embargo, es hora de pasar de la teoría a la praxis, trabajar en la propia concientización. Es imperante que se aprenda a ver, sentir y actuar como parte importante del sistema ecológico, complejo, interrelacionado, interactivo aún sin darse cuenta.

En el caso del aprendizaje de la Arquitectura, este debe apuntar a proyectar espacios interiores, edificaciones y ciudades que muestren $y$ demuestren su vocación sostenible, que ofrezcan a las personas lugares para habitar y no cajas para guardar, espacios para vivir y convivir, para disfrutar del trabajo, del estudio, de la familia, los vecinos, los ciudadanos. Esto, en consonancia y armonía con el medio ambiente local, autóctono, sobre la base del respeto, la valorización, la protección que se le dé al ambiente natural y construido, utilizándolo en favor del bien común a través de buenas prácticas sostenibles, en el tiempo y en el espacio.

\section{3a. Reflexión. ¿Lugares para habitar o cajas para guardar?}

Como hacer y como profesión, la Arquitectura comporta la búsqueda de soluciones cónsonas para el hábitat humano, considerando múltiples variables intervinientes que debemos considerar 
al momento de hacer arquitectura. Estas variables, que pueden comportar tanto una movilidad cualitativa como una cuantificable, consideran desde las morfoestéticas, relativas a la forma y el criterio de belleza, pasando por las funcionales, que consideran las actividades y la utilidad; las espaciales, relativas al espacio y sus cualidades; las técnico-constructivas, relacionadas con aspectos estructurales y materiales; las ambientales, que involucran aspectos naturales y artificiales del entorno; las histórico contextuales, que implican el entorno socio-cultural-histórico; y, por último, no obstante, la primera que debe considerarse: la variable humana, eje y centro neurálgico de nuestra disciplina, que abordan nuestra relación con todas las demás variables, incluidos nosotros mismos y nuestro interior.

Al analizar esta reflexión, "Porque la casa es nuestro rincón del mundo. Eso es -se ha dicho con frecuencia-, nuestro primer universo. Es realmente un cosmos. Un cosmos en toda la acepción del término." (Bachelard, 1957, p. 28), es evidente la clara la alusión a las significaciones de la casa y cuanto esta involucra para quien la habita: su intimidad, su cosmos, su ideal de belleza más allá de la estética visual.

De lo anterior, surge la interrogante: ¿quién mejor para referirse a un lugar que quien allí reside? Sus respuestas, más aún si son espontáneas, arrojan pistas para imaginar, dibujar, diseñar y crear, pues remiten a la cultura de esa persona, a sus necesidades, valores y aspiraciones, a sus maneras de visualizar el mundo y, en consecuencia, de vivirlo. ¿Podría hablarse de una estética del alma? Esa experiencia vivida en el espacio habitable interesa profundamente a quien trabaja en Arquitectura, sea estudiante, profesor o profesional, en tanto que, a partir de costumbres, estilos, vivencias, necesidades, expectativas, modos de ser, de vivir y de sentir, se desprende la esencia de la disciplina como ciencia, arte y rama del saber, cuyo accionar se centra en los espacios habitables, los seres que los habitan y que en ella conviven.

Al respecto, cuando se quiere hacer Arquitectura "hay que decir, pues, cómo habitamos nuestro espacio vital de acuerdo con todas las dialécticas de la vida, cómo nos enraizamos, de día en día, en un 'rincón del mundo'"' (Bachelard, 1957, p. 28). Es necesario adentrarse más allá del objeto-espacio, sea este una ciudad, una casa, una escuela, un hospital, un parque, o tantos otros inherentes al hacer del Arquitecto, para conocer a quien los vive y transforma en espacios vividos, y desde allí emprender el acto de diseñar.
Son las personas que habitan el lugar, quienes transforman los espacios en lugares para habitar. Lamentablemente son los Arquitectos quienes en innumerables ocasiones se empeñan en ofrecerles cajas para guardar, dispuestas como cajones o gavetas muchas veces sin ninguna estética, una sobre otra, o al lado de esta, organizadamente como una suerte de armario donde deben caber vivencias, sueños, luchas, esfuerzos, temores, aspiraciones en $60 \mathrm{~m}^{2}$ y hasta en $40 \mathrm{~m}^{2}$. Esas, las denominadas construcciones formales, sin embargo, son mayoritarias las informales. Ahí también se tejen sueños y se construyen realidades.

\section{4a. Reflexión. ¿Se enseña a diseñar para quién?}

Como resultado de la interacción entre el espacio y los seres que los habitan surgen las esencias del lugar. (Linares, 2017, p.77). Sentimientos, percepciones, emociones, sensaciones, no solo desde la óptica de quien vive y convive en el lugar, sino también de quien lo ha proyectado o construido como espacio habitable. Al intentar entender las significaciones que un recinto patrimonial tiene para una determinada ciudad, no basta con indagar en libros de historia, sino también, y, primeramente, en las personas: usuarios, residentes, trabajadores, turistas, también en el proyectista y en el constructor.

De igual modo, como Arquitectos se debe indagar sobre otros aspectos no menos importantes: como la presencia y convivencia en el espacio de plantas y animales, analizar sus propias interacciones como seres vivos con el lugar a partir de la observación. Es posible entonces examinar la luz natural que incide en un lugar para el crecimiento de una flor o un árbol, cómo utiliza una mascota un sitio específico para dormir la siesta, cómo las personas se sientan frente a la fachada de un edificio y se dejan bañar por sus memorias, cómo el olor a pan recién horneado atrae e invita a compartir un rato de esparcimiento en la plaza.

Todas esas observaciones multisensoriales, arrojan pistas sobre la esencia del lugar y su significación, tanto para sus habitantes de forma individual como en el colectivo de una ciudad, siendo de gran utilidad al analizar, entender o intervenir cualquier espacio y/o ciudad. De ese modo, a partir del carácter reflexivo en la exploración de la experiencia vivida, es posible abordar el aprendizaje y la subsecuente práctica de la Arquitectura, como profesión y área del saber. De la confluencia de grandes ríos de conocimiento: lo técnico, lo artístico y lo social que desembocan juntos y se entremezclan en un vasto mar, surge la Arquitectura. De esa tri-unidad "... 
surge un factor común que ha definido la esencia de la arquitectura; éste es la habitabilidad como creación de espacio en el sentido fenomenológico, es el espacio que se crea en tanto el ser que lo habita y se identifica con él, ahora sí, desde lo tecnológico, lo artístico y lo funcional." (Palacio, 2016, p.40).

Claramente, el referido autor hace referencia a dos aspectos precisos: habitabilidad e identificación. El primero, apunta a lo práctico del hecho arquitectónico: servicios, funcionalidad espacial y estructural, aplicación de normativas. El segundo aspecto, alude a la unión del ser humano con su espacio, el sentido de pertenencia, de apropiación positiva del espacio, no solo el construido sino también el natural, que hace que el ser humano proteja y valore, a la vez que disfrute, su entorno inmediato.

Lo anterior, respalda una enseñanza y un aprendizaje de la Arquitectura fundados en valores de humanidad, tanto individuales como sociales compartidos hacia la casa de todos. De esa manera, "...la integración teórica y práctica en el ámbito de la educación para la sustentabilidad no sólo implica saber $y$ hacer, sino que, en la medida que actuamos guiados por motivos que tienen que ver con un sistema de valores colectivos, apelando a un tipo de formación sobre valores, es decir, a un tipo de saber de carácter ético, compromisos que orientan la acción." (Arrieta y Ferrer, 2012. p.29). Lo anterior, refleja la enseñanza fundamentada en valores, que debe ser acometida por todos si se quiere transformar las prácticas y el vivir en un buen vivir.

\section{5a. Reflexión. ¿Calidad de vida o vida de calidad?}

Al enfrentar situaciones extremas, como carencia de servicios indispensables: sistema de salud, educación, agua potable, energía eléctrica, sistema de transporte y telecomunicaciones, espacios públicos adecuados, ciertamente salta la pregunta: ¿esto es calidad de vida? La Organización Mundial de la Salud, cuando explica que la calidad de vida es "...la percepción individual de la posición en la vida en el contexto de la cultura y sistema de valores en el cual se vive y su relación con las metas, expectativas, estándares e intereses." (Urzúa y Caqueo-Urizar, 2012, p. 65). Entonces, ¿qué calidad de vida tiene un habitante de las ciudades latinoamericanas en general? ¿Se habita en una ciudad sustentable? Lamentablemente el diario vivir está rodeado de graves dolencias, incongruencias, necesidades. ¿Vida de calidad?

Hacia esas carencias debe apuntar el papel docente, a hacer más evidentes esas realidades y a despertar en los estudiantes de Arquitectura el interés por investigar, profundizar y proponer sobre esos temas cotidianos que afectan a todos y que apuntan por desmejorar cada vez más la calidad de vida. El hacer docente debe orientarse, ahora más que nunca, por propulsar una vida de calidad a través de los espacios habitables, no sólo los nuevos por construir, sino también los ya habitados, aquellos que son patrimonio, que conducen a apropiarse del lugar, espacios públicos reunitivos diseñados para el vivir y el convivir. A ese respecto, "Hace falta cuidar los lugares comunes, los marcos visuales y los hitos urbanos que acrecientan nuestro sentido de pertenencia, nuestra sensación de arraigo, nuestro sentimiento de "estar en casa» dentro de la ciudad que nos contiene y nos une." (Francisco, 2015, p.117).

El ser humano merece una vida de calidad, y para ello no puede quedarse en la teoría, debe pasar a la práctica del buen vivir. El apoyo para ello debe provenir de todos los ámbitos, no obstante, el educativo, el académico tiene una especial responsabilidad, porque es a partir de una educación fundada en la sostenibilidad como podrá enrumbarse hacia una vida de calidad con espacios, ciudades, países y un planeta sostenible.

\section{Conclusiones}

La sostenibilidad alude a múltiples aristas. La educación, especialmente el aprendizaje de la Arquitectura, debe propender a la gestación, construcción, mantenimiento y protección no sólo de espacios cada vez más armoniosos con la vida natural, sino también con permanencia en el tiempo, considerando para ello las necesidades de la sociedad que les da vida y las condiciones socioeconómicas, institucionales, educativas, culturales y políticas que promuevan satisfacción en las personas. Un indicador de que se está conduciendo hacia el entendimiento del significado de calidad de vida, es a través de la satisfacción de las necesidades básicas, del ofrecimiento de buenos servicios públicos, vivienda, salud, educación, entretenimiento, sistemas de seguridad social, aunado al transporte y las comunicaciones.

De ese modo, la búsqueda del aprendizaje de la Arquitectura debe orientarse hacia las buenas prácticas para la sostenibilidad, de modo que se alcancen hábitats tanto agradables como sanos, en los que esta generación y las futuras puedan encontrar espacios propicios para el desarrollo del conocimiento, el pensamiento y el arte, el deporte, los movimientos culturales, el ocio, no obstante, así mismo para vivienda, educación, servicios de salud y de aprovisionamiento. Hay que construir el 
lugar y este solo surge de sus propios habitantes, las soluciones surgen de allí, no pueden ser trasplantadas sin tener en cuenta las condiciones y reales necesidades de las personas y de los contextos naturales.

Sin ánimos de adoctrinar, no obstante, con la convicción cierta que la sostenibilidad debe cimentarse en una nueva moral, en la bioética, no solo centrada en necesidades de agua, energía y manejo de desechos, las cuales, aunque prevalentes para el asentamiento de las personas en un territorio, deben estar subrogadas por un pensamiento y un accionar moralmente concertado sobre el buen vivir y la vida de calidad que todos los seres merecen. De este modo, al trabajar desde la educación, hacia el aprendizaje de la Arquitectura, los esfuerzos no debieran caer en saco roto, pues se está formando a un ser humano, a un Arquitecto con visión, creencias, cualidades y competencias para la sostenibilidad.

\section{REFERENCIAS}

Arrieta, R.; Ferrer, T. (2012) Arquitectura contemporánea y desarrollo sustentable. Perspectiva, 1 (1),16-32. https://produccioncientificaluz.org/index.php/perspectiva/article/view/17724

Edwards, B. (2009) Guía básica de sostenibilidad. Barcelona. España: Editorial Gustavo Gili.

Esteves, M.; Salas, R; Dalla Torre, J. (2018) El paisaje cultural como herramienta en la gestión del hábitat y el territorio. Mundo Urbano, 50, 1-11. http://www.mundourbano.unq.edu.ar/index. php/ano-2018/286-el-paisaje-cultural-como-herramienta-en-la-gestion-del-habitat-y-el territorio?tmpl=component\&print=1\&layout=default\&page $=$

Francisco. (2015) Carta encíclica Laudato Si.' Sobre el cuidado de la casa común. Documento en línea. Recuperado de: https://www.vidanuevadigital.com/wp-content/uploads/2015/06/Laudato-Si-ES.pdf

Gabaldón, A. (2006) Desarrollo sustentable. La salida de América Latina. Caracas. Venezuela: Editorial Grijalbo.

Heidegger, M. (1951) Construir, habitar, pensar. Documento en línea. Recuperado de: http://www.lugaradudas. org/archivo/publicaciones/fotocopioteca/39_heidegger.pdf

Linares, M. (2017). La indagación fenomenológica: herramienta para el abordaje del aprendizaje del diseño arquitectónico. Designia, 5(1), 68-82. https://doi.org/10.24267/22564004.250

Real Academia Española. (2020). Diccionario de la lengua española. https://www.rae.es/ . Consultado el 18 de marzo de 2020.

Palacio, B. (2016). La enseñanza integral de la Arquitectura, desde la perspectiva de la sostenibilidad ambiental. Módulo Arquitectura CUC, 16(1), 35-58. http://doi.org/10.17981/mod.arq.cuc.22.1.2019.03

Urzúa, A., Caqueo-Urizar, A. (2012) Calidad de vida: Una revisión teórica del concepto. Terapia Psicológica, 30(1), 61-71. http://dx.doi.org/10.4067/S0718-48082012000100006 